\title{
GIBERELINA E SUBSTRATOS NA PRODUÇÃO E QUALIDADE DE MUDAS DE ARAÇAZEIROS AMARELO E VERMELHO
}

Alexandre Hack Porto, Américo Wagner Júnior, Carlos Kosera Neto, Marciéli Da Silva, Alberto Ricardo Stefeni, Kamila Cristina Fabiane

Universidade Tecnológica Federal do Paraná - UTFPR, Programa de Pós-Graduação em Agronomia, câmpus Pato Branco e Dois Vizinhos, PR. E-mail: alexandrehack@gmail.com

\section{RESUMO}

Na região Sul do país as fruteiras têm papel importante, pois podem servir para exploração econômica. Destacando-se a família Myrtaceae, com fruteiras como araçazeiro. Porém, pouco se conhece sobre a espécie, tornando-se necessários mais estudos principalmente quanto à propagação para futura inserção no sistema de produção agrícola da região Sudoeste do Paraná ou para abastecer o mercado que carece desses produtos. Com isso, objetivou-se com este trabalho avaliar o crescimento e desenvolvimento de mudas dos araçazeiros amarelo e vermelho em diferentes substratos com apliçção exógena de giberelina. O experimento foi conduzido na Universidade Tecnológica Federal do Paraná - Câmpus Dois Vizinhos em casa de vegetação. O delineamento experimental utilizado foi inteiramente casualizado, no fatorial $3 \times 4$ (substrato, concentração de $\mathrm{GA}_{3}$ ), com quatro repetições de 20 plantas por unidade experimental. Foram analisadas variáveis destrutíveis e não destrutíveis de crescimento e o índice de qualidade de mudas de Dickson. Os dados foram submetidos a análise de variância, teste de Duncan e análise de regressão, utilizando o aplicativo computacional estatístico Sanest ${ }^{\circledR}$. As concentrações de $\mathrm{GA}_{3}$ e os tipos de substratos influenciaram o desenvolvimento de mudas de araçazeiros. O uso do substrato (S3) associado ao fitoregulador giberelina é recomendado para a produção de mudas de araçazeiro amarelo e vermelho.

Palavras-chave: fitoregulador; propagação; Myrtaceae; Psidium cattleyanum Sabine.

\section{GIBBERELLIN AND SUBSTRATES IN THE PRODUCTION AND QUALITY OF YELLOW AND RED STRAWBERRY GUAVA TREES SEEDLINGS}

\begin{abstract}
In the South of the country, the fruit has an important role, with potential for economic exploitation, which highlights those of the Myrtaceae family, with fruit tree such as strawberry guava. However, little is known about the species. Thus become more research is necessary, especially as the spread for future inclusion in the agricultural production system of Paraná Southwest region as well as to supply the market needs these products. The objective of this study was to evaluate the growth and development of seedlings of yellow and red Brazilian guava trees on different substrates with exogenous application of gibberellic acid. The experiment was conducted at the Universidade Tecnológica Federal do Paraná - Campus Dois Vizinhos. In the greenhouse was used completely randomized design in factorial $3 \times 4$ (substrate concentration GA3), with four replicates of 20 plants each. They were analyzed non destructible and destructible growth variables, nd quality index of Dickson seedlings. Data were subjected to analysis of variance, Duncan test and regression analysis using the statistical computer application Sanest ${ }^{\circledR}$. The concentrations of GA3 and substrates influencing the development of Brazilian guava trees seedlings, thus it is concluded that the use of the substrate (S3) associated with the gibberellin plant growth regulator is recommended for the production of seedlings of strawberry guava yellow and red.
\end{abstract}

Keywords: phytoregulator; propagation; Myrtaceae; Psidium cattleyanum Sabine. 


\section{INTRODUÇÃO}

O Brasil é conhecido como um dos principais centros de diversidade genética de fruteiras silvestres do mundo (HEINZMANN; BARROS, 2007). Apesar disso, se conhece pouco sobre a grande maioria destas espécies. $\mathrm{Na}$ região Sul do país, as fruteiras têm papel importante, apresentando grande potencial para exploração econômica, onde se destacam espécies da família Myrtaceae (DANNER et al., 2010), por apresentarem capacidade de ampla adaptação edafoclimática que permite utilizá-las em pomares domésticos e comerciais e para recuperação de ecossistemas degradados.

Dentro dessas espécies, o araçazeiro (Psidium Cattleyanum Sabine) apresenta distribuição em diversos biomas, cujo destaque se refere ao potencial para exploração econômica, pois seus frutos podem ser consumidos in natura ou industrializados, utilizados com fins alimentares ou também medicinais (LORENZI, 1992; HISTER; TEDESCO, 2016).

Porém, o país pouco aproveita a potencialidade presente nas espécies nativas, com exceção de algumas já consolidadas como goiabeira, maracujazeiro, guaranazeiro, açaizeiro e cajueiro. Todavia, a oportunidade de alçar no mercado produtos diferenciados como 0 araçazeiro, com potencial econômico que podem gerar complemento de renda para o pequeno agricultor e permanência da população no campo.

Para isso, tornam-se necessários mais estudos principalmente em relação a sua propagação, pois a oferta de mudas com qualidade, facilita sua inserção no sistema de produção agrícola e somente assim, esta espécie pode passar de negligenciada para realidade nos mercados (KINUPP; BARROS, 2008).

A propagação do araçazeiro é realizada principalmente por sementes, sendo o método mais satisfatório, cujas taxas de germinação podem alcançar valores acima de $95 \%$, mesmo quando submetidas ao armazenamento (RASEIRA; RASEIRA, 1996; TOMAZ et al., 2011). Outrossim é o fato do araçazeiro apresentar difícil propagação pelo método vegetativo, pelo acúmulo de compostos fenólicos que em contato com o ar, ocasionam oxidação dos tecidos (FRANZON et al., 2009) e pelas mudas geradas apresentar grande homozigose pela presença de apomixia.
Para produção de mudas de qualidade alguns fatores devem ser considerados, como o substrato e o uso de reguladores de crescimento, como as giberelinas. $O$ substrato ideal para produção de mudas deve apresentar características que possibilita que a planta inicie o ciclo de forma satisfatória e futuramente expresse o máximo potencial genético. Essas características dos substratos estão associadas a homogeneidade, baixa densidade, drenagem satisfatória, retenção de água, espaço de aeração, boa capacidade de campo, troca catiônica, fonte de nutrientes, ser isento de pragas, organismos patogênicos e sementes de plantas invasoras, devendo ter de baixo custo, fácil acesso e disponível na região (FONTES et al., 2004; PAIVA SOBRINHO et al., 2010).

As giberelinas são hormônios ou bioestimulantes internos dos vegetais que atuam em seu ciclo de vida. Quando utilizados na forma exógena podem acelerar $o$ crescimento e desenvolvimento, pois atuam diretamente no alongamento, divisão celular, na permeabilidade da membrana celular, na atividade enzimática, na variação em potencial osmótico e na mobilização de açúcares. Porém, o efeito deste bioestimulante além de ser dependente dos fatores ambientais, depende também da concentração, do número de aplicações, da época de aplicação e da espécie ou cultivar em uso (WAGNER JÚNIOR et al., 2012).

Desta forma, remete o objetivo aos autores avaliarem a aplicação de giberelina e o uso de diferentes substratos na produção e qualidade de mudas de araçazeiros amarelo e vermelho.

\section{MATERIAL E MÉTODOS}

O trabalho foi realizado em Casa de Vegetação, da Unidade de Ensino e Pesquisa Viveiro de Produção de Mudas Hortícolas, da Universidade Tecnológica Federal do Paraná Câmpus Dois Vizinhos. No interior da Casa de Vegetação em ambiente controlado, o ambiente foi programado para manter temperatura controlada de $25^{\circ} \mathrm{C}$ e umidade relativa a $90 \%$.

Foram utilizadas sementes de araçazeiro amarelo "Ya-Cy" coletadas, manualmente, de frutos sadios e em estádio de maturação com a presença da epiderme com $100 \%$ de totalidade amarelada, sendo estes oriundos de plantas do pomar de fruteiras nativas da referida instituição. $\mathrm{O}$ mesmo procedeu-se com araçazeiro vermelho nativo. 
Após a coleta dos frutos, foram extraídas as sementes em peneira de aço com uso de água corrente. Em seguida, as sementes extraídas foram mantidas a sombra por 48 horas para secagem e semeadas após esse período. Decorridos 30 dias da emergência das plântulas, em sementeira contendo areia como substrato, as mesmas foram transplantadas para tubetes de volume $90 \mathrm{~cm}^{3}$ contendo três tipos de substratos.

Estes substratos utilizados foram constituídos por latossolo+areia (1:1 v/v) (S1), substrato comercial (S2) e latossolo+areia+cama de aviário (1:1:0,5 v/v/v) (S3). Para mistura, peneirou-se todos os componentes da formulação dos substratos para que ficassem livres de impurezas e agregados maiores, sendo a homogeneização feita em betoneira de construção civil. Amostras das misturas dos substratos foram enviadas para o Laboratório de Solos da UTFPR - Câmpus Pato Branco, no qual fez-se sua caracterização química por meio dos teores de nutrientes $(\mathrm{P}, \mathrm{K}, \mathrm{Ca}$ e $\mathrm{Mg})$, $\mathrm{Al}$, Soma de bases (SB), pH, CTC, matéria orgânica (M.O.) (Tabela 1).

Tabela 1. Características químicas de três substratos utilizados para produção de mudas de araçazeiros amarelo e vermelho

\begin{tabular}{|c|c|c|c|c|c|c|c|c|c|c|}
\hline \multirow[t]{2}{*}{ Substrato } & $\mathrm{pH}$ & $\mathrm{P}$ & K & $\mathrm{Ca} 2+$ & Mg2+ & $\mathrm{Al} 3+$ & $\mathrm{H}+\mathrm{Al}$ & SB & $\begin{array}{l}\text { CTC } \\
\text { (T) }\end{array}$ & \multirow{2}{*}{$\frac{\mathrm{MO}}{\mathrm{gdm}-3}$} \\
\hline & $\mathrm{CaCl} 2$ & \multicolumn{2}{|c|}{$m g d m-3$} & \multicolumn{6}{|c|}{ cmolc dm-3 } & \\
\hline S1 & 5,3 & 19,88 & 50,83 & 4 & 1,5 & 0,13 & 2,74 & 5,63 & 8,37 & 1,34 \\
\hline S2 & 5,1 & 165,14 & 469,2 & 6 & 7,1 & 0,06 & 4,59 & 14,3 & 18,89 & 83,09 \\
\hline S3 & 6,6 & 2430,08 & 254,15 & 6,6 & 7,2 & 0 & 2,19 & 13,95 & 16,14 & 32,17 \\
\hline
\end{tabular}

(S1) Latossolo+areia - 1:1 v/v; (S2) Substrato comercial para plantas; (S3) Latossolo+areia +cama-de-aviário - 1:1:0,5 v/v/v, Metodologias: M.O. por digestão úmida; P e K extraídos com solução de Mehlich - I; $\mathrm{pH}$ em $\mathrm{CaCl}_{2} 1: 2,5 ; \mathrm{Ca}, \mathrm{Mg}$ e Al trocáveis extraídos com $\mathrm{KCl} 1 \mathrm{~mol} \mathrm{~L}^{-1}$.

A aplicação exógena de giberelina $\left(\mathrm{GA}_{3}\right)$ foi realizada 30 dias após transplante das mudas, repetindo-o 30 dias após a primeira aplicação. Foram utilizadas quatro concentrações de $\mathrm{GA}_{3}$, sendo estes de $0,100,200$ e $300 \mathrm{mg} \mathrm{L}^{-1}$, preparados por meio do produto comercial Pro$\mathrm{Gibb}^{\circ}$ que contém $10 \%$ de $\mathrm{GA}_{3}$. A diluição do produto foi em água destilada e deionizada com auxílio de agitador magnético e acrescentando-se água novamente para completar a solução, formando-se volume 1:1 (v/v), de acordo com cada concentração a ser testada.

A casa de vegetação continha irrigação por nebulização com oito turnos de funcionamento diário por 30 minutos de funcionamento.

Foi utilizado delineamento experimental inteiramente casualizado (DIC), em fatorial $3 \times 4$ (substrato $x$ concentração de $\mathrm{GA}_{3}$ ), com quatro repetições e 20 plantas por unidade experimental, para ambas espécies de araçazeiros.

Após 180 dias da implantação do experimento procedeu-se com as avaliações de altura $(\mathrm{cm})$ e porcentagem de sobrevivência na casa de vegetação. Em seguida, o material foi retirado dos tubetes e levados para Laboratório de Fisiologia Vegetal, devidamente identificado para realização das avaliações destrutivas de volume de raízes expressos em mililitros $(\mathrm{mL})$, comprimento da parte aérea $(\mathrm{cm})$ e comprimento da raiz $(\mathrm{cm})$, diâmetro de colo $(\mathrm{mm})$, número de folhas, área foliar de três folhas por planta $\left(\mathrm{cm}^{2}\right)$, comprimento e largura das folhas $(\mathrm{cm})$ e teor de clorofila expressos pelo índice de clorofila falker e determinado o índice de qualidade de mudas.

O volume de raízes foi mensurado com auxílio de bureta graduada e água, onde imergiram-se as raízes e subtraindo-se o valor do volume de água (BIASI; COSTA, 2003). O comprimento de raízes, comprimento da parte aérea, largura e comprimento de folhas foi executado com régua graduada $(\mathrm{cm})$. $O$ diâmetro de colo com paquímetro digital ajustado na escala de milímetros ( $\mathrm{mm}$ ), a área foliar com laser scanner modelo CID bio-science e o teor de clorofila total com clorofilômetro modelo Clorofilog FALKER ${ }^{\circ}$.

$O$ índice de qualidade de Dickson (IQD) foi determinado em função da massa da matéria seca total, altura da parte aérea (ALT), do diâmetro do colo (DIAM), fitomassa seca da parte aérea (MSPA) que é dada pela soma da fitomassa seca do caule e a fitomassa seca de folhas e da fitomassa seca das raízes (MSR) (DICKSON et al., 1960). 
Em seguida, as plantas foram separadas em raiz, caule e folhas e colocadas em estufa de secagem a $105^{\circ} \mathrm{C}$ por três dias, atingindo peso constante, para avaliação de massa de matéria seca.

Os dados foram submetidos a análise de variância, teste de comparação de médias de Duncan para o fator qualitativo e interação entre fatores e, de regressão para o fator quantitativo, utilizando o aplicativo computacional estatístico Sanest ${ }^{\circ}$ (ZONTA; MACHADO, 1984). Previamente, os dados foram submetidos ao teste de normalidade de Lilliefors no programa Genes (CRUZ, 2006). As variáveis respostas de comprimento de raiz, comprimento da parte aérea e número de folhas do araçazeiro amarelo e, comprimento de raiz, comprimento da parte aérea, número de folhas, área foliar e comprimento de folha do araçazeiro vermelho não sofreram transformações de médias.

As variáveis volume de raiz, diâmetro de colo, largura de folha e clorofila de ambos araçazeiros e massa de matéria seca de folhas, massa de matéria seca de caule, massa da matéria seca de raiz do araçazeiro vermelho e comprimento de folha do araçazeiro amarelo segundo foram transformados por $\vee x+1$, a área foliar, massa da matéria seca de folhas, massa da matéria seca de caule e massa da matéria seca de raiz do araçazeiro amarelo e a porcentagem de sobrevivência de ambos foram transformados segundo $\operatorname{arcsen} v x / 100$.

\section{RESULTADOS E DISCUSSÃO}

Analisando-se a Tabela 2, verificou-se superioridade no uso do substrato $\mathrm{S} 3$ em todas as concentrações de $\mathrm{GA}_{3}$ para o crescimento em altura do araçazeiro amarelo. Para o araçazeiro vermelho, as maiores médias para essa variável, na concentração de 0 de $\mathrm{GA}_{3}$ foram com S3 e S1, sendo que nas demais concentrações repetiu-se a superioridade obtida com S3.
O substrato $\mathrm{S} 3$ apresentou possivelmente a melhor faixa de MO para o bom crescimento da muda, uma vez que, obtém-se do mesmo, nutrientes como nitrogênio, responsável pela síntese de proteínas necessárias para o crescimento. Como o valor obtido deste substrato (S3), esteve na faixa intermediária, não demonstrou com isso excesso ou falta que podem ter interferido nas respostas obtidas em comparação aos demais substratos (S2 e S1).

Além disso, o alto teor de fósforo verificado no S3 pode também ter favorecido para esse resultado, uma vez que, ele está ligado a síntese de energia, favorável e necessária para as rotas metabólicas do crescimento do vegetal (TAIZ; ZEIGER, 2013).

Outro ponto diz respeito ao $\mathrm{pH}$ deste substrato, estando praticamente na faixa considerada ótima para muda $(5,5$ a 6,5$)$ (OLIVEIRA et al., 2015) em relação aos demais.

Quanto ao uso de ácido giberélico $\left(\mathrm{GA}_{3}\right)$ com a utilização do substrato $S 1$, a aplicação de $100,200,300 \mathrm{mg} \mathrm{L}^{-1}$ de $\mathrm{GA}_{3}$ e para o S3 de 200 e $300 \mathrm{mg} \mathrm{L}^{-1}$ proporcionaram a maior altura nas mudas de araçazeiro amarelo. Quanto ao substrato S2, as médias não diferiram estatisticamente entre si para essa variável com tal variedade botânica (Tabela 2 ).

Por outro lado, com araçazeiro vermelho, dentro do substrato S1 as maiores médias de altura foram nas concentrações de 100, 200, 300 $\mathrm{mg} \mathrm{L}^{-1}$ de $\mathrm{GA}_{3}$, para S2 com 0, 100 e $300 \mathrm{mg} \mathrm{L}^{-1} \mathrm{e}$, com S3 com $300 \mathrm{mg} \mathrm{L}^{-1}$ (Tabela 2).

Isso serve para demonstrar que as concentrações podem apresentar diferentes respostas quanto ao substrato a ser utilizado para cada espécie ou variedade botânica. Todavia, o que foi possível constatar que parece haver maior efeito do crescimento em altura destas fruteiras com incremento na concentração aplicada, independente do substrato. 
Tabela 2. Crescimento em altura $(\mathrm{cm})$ de mudas de araçazeiros amarelo e vermelho submetidos a três tipos de substratos e quatro concentrações de $\mathrm{GA}_{3}$ no período de 180 dias acondicionadas em casa de vegetação.

\begin{tabular}{|c|c|c|c|}
\hline \multicolumn{4}{|c|}{ ARAÇA AMARELO } \\
\hline \multirow{2}{*}{$\mathrm{GA}_{3}\left(\mathrm{mgL}^{-1}\right)$} & LATOSSOLO + AREIA & COMERCIAL & LATO+AREIA+ CAMA AV. \\
\hline & $\mathrm{S} 1$ & S2 & S3 \\
\hline 0 & $5,75 b^{*}$ & 3,25 a C & $8,75 \mathrm{~b} \mathrm{~A}$ \\
\hline 100 & 7,5 ab B & 4 a C & 10,25 b A \\
\hline 200 & 8,75 a $B$ & 4,5 a C & 14 a A \\
\hline 300 & 9,25 a B & $3,25 \mathrm{ab} B$ & 14,5 a $\mathrm{A}$ \\
\hline CV (\%) & & 18,87 & \\
\hline \multicolumn{4}{|c|}{ ARAÇA VERMELHO } \\
\hline 0 & $5,37 \mathrm{~b} \mathrm{AB} *$ & $4,54 a b B$ & 7,00 c A \\
\hline 100 & 8,61 a B & $4,22 a b C$ & 11,72 b A \\
\hline 200 & 8,60 a $B$ & $3,83 \mathrm{~b} \mathrm{C}$ & 11,68 b A \\
\hline 300 & 8,58 a B & 5,49 a $C$ & 15,99 a $A$ \\
\hline CV (\%) & & 7,4 & \\
\hline
\end{tabular}

*Médias seguidas por letras minúsculas distintas na coluna e maiúsculas na linha, diferem significativamente entre si pelo teste de Duncan $(\alpha=0,05)$.

$\mathrm{O} \mathrm{GA}_{3}$ apresenta papel importante na divisão e alongamento celular uma vez que promove o aumento da extensibilidade e da plasticidade da parede celular, devido à orientação das microfibrilas de celulose, atuando em células jovens e meristemáticas (SCALON et al., 2009), sendo percebido no alongamento do caule, comprimento dos entrenós, área foliar e acúmulo de massa da matéria seca. Tais características puderam ser visualizadas no presente trabalho com os resultados apresentados na Tabela 2 e na Figura 2, no caso do araçazeiro amarelo e Tabelas 4, 7 e $11 \mathrm{com}$ o araçazeiro vermelho.
Torres e Borges (2013) relataram que o crescimento das plantas em altura deve-se a capacidade do $\mathrm{GA}_{3}$ em estimular a divisão celular na expansão do caule e alongamento da planta.

Segundo Taiz e Zeiger (2013) esse fato ocorre porque as giberelinas estimulam a síntese de enzimas hidrolíticas, que atuam sobre amidos, proteínas e aminoácidos, liberando energia para síntese protéica, necessária para o desenvolvimento das plantas.

Em relação a sobrevivência das plantas, com araçazeiro amarelo obteve-se comportamento linear crescente de acordo com aumento nas concentrações de $\mathrm{GA}_{3}$, chegando-se a $100 \%$ com $300 \mathrm{mg} \mathrm{L}^{-1}$ (Figura 1 ).

Figura 1. Porcentagem de sobrevivência de araçazeiros amarelos submetidos a quatro concentrações de $\mathrm{GA}_{3}\left(\mathrm{mg} \mathrm{L}^{-1}\right)$

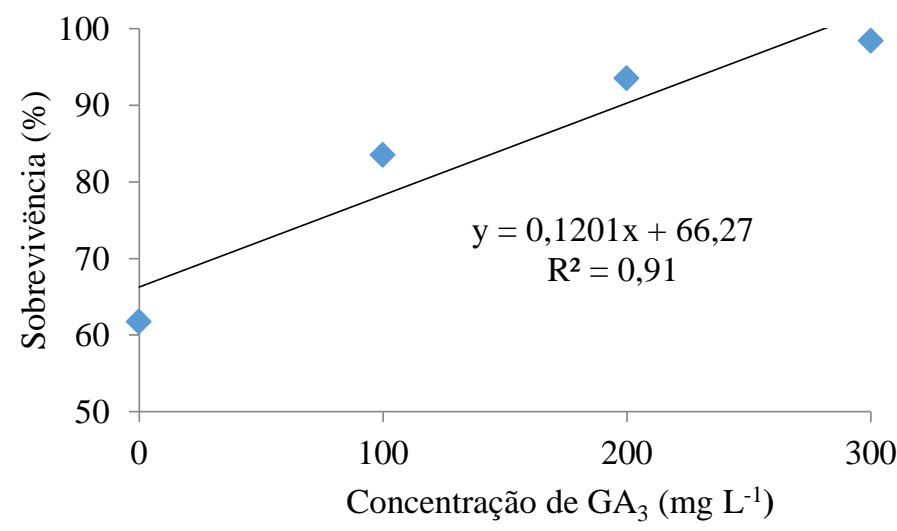

Por outro lado, para o araçazeiro vermelho a interação entre os fatores mostrou-se significativa, tendo para concentrações de $0 \mathrm{mg} \mathrm{L}^{-}$
${ }^{1}$ de $\mathrm{GA}_{3}$ quando aplicado em conjunto com S3 promoveu efeito negativo, o mesmo foi visualizado na aplicação $300 \mathrm{mg} \mathrm{L}^{-1}$ de $\mathrm{GA}_{3}$ 
utilizando o S1, isso demostra que a combinação correta de bioestimulante aliado ao uso ao uso de substrato ideal para cada cultura pode influenciar na sobrevivência de mudas (Tabela 3).

Tabela 3. Sobrevivência (\%) de mudas de araçazeiros vermelho submetidos a três tipos de substratos e quatro concentrações de $\mathrm{GA}_{3}$ no período de 180 dias acondicionadas em casa de vegetação

\begin{tabular}{cccc}
\hline \multirow{2}{*}{$\mathrm{GA}_{3}\left(\mathrm{mgL}^{-1}\right)$} & LATOSSOLO + AREIA & COMERCIAL & LATO+AREIA+ CAMA AV. \\
\cline { 2 - 4 } & S1 & S2 & S3 \\
\hline 0 & $94,18 \mathrm{ab} \mathrm{A}$ & $96,53 \mathrm{a} \mathrm{A}$ & $69,45 \mathrm{a} \mathrm{B}$ \\
100 & $91,50 \mathrm{ab} \mathrm{A}$ & $99,68 \mathrm{a} \mathrm{A}$ & $89,66 \mathrm{ab} \mathrm{A}$ \\
200 & $98,14 \mathrm{a} \mathrm{A}$ & $93,63 \mathrm{a} \mathrm{A}$ & $95,43 \mathrm{a} \mathrm{A}$ \\
300 & $75,70 \mathrm{~b} \mathrm{~B}$ & $100,00 \mathrm{a} \mathrm{A}$ & $98,14 \mathrm{a} \mathrm{A}$ \\
\hline $\mathrm{CV}(\%)$ & & 16,8 & \\
\hline
\end{tabular}

*Médias seguidas por letras minúsculas distintas na coluna e maiúsculas na linha, diferem significativamente entre si pelo teste de Duncan $(\alpha=0,05)$.

Ressaltando-se a sobrevivência do araçazeiro vermelho em cada substrato, verificou-se que para o S1 as maiores médias foram obtidas com concentrações de 0 a $200 \mathrm{mg}$ $\mathrm{L}^{-1}$, para o S3 de 100 a $300 \mathrm{mg} \mathrm{L}^{-1}$ e para o S2 as quatro concentrações não diferiram estatisticamente entre si.

Dessa forma, visualizou se que apesar do uso de $300 \mathrm{mg} \mathrm{L}^{-1}$ de $\mathrm{GA}_{3}$ aplicado no araçazeiro vermelho com S1 ter proporcionado maior crescimento, estes geraram menor sobrevivência, o que pode estar ligado ao fato dessa concentração ser considerada limite para fitotoxidez desta fruteira.

Observando-se a Tabela 4, as variáveis volume e comprimento de raízes e, o comprimento da parte aérea tiveram significância com o fator substrato, cujo resultados apresentaram superioridade com S3 para produção de mudas de araçazeiros amarelo.

Tabela 4. Volume de raízes $(\mathrm{mL})$, comprimento de raízes e crescimento da parte aérea $(\mathrm{cm})$ de mudas de araçazeiros amarelo submetidos a três tipos de substratos, no período de 180 dias, acondicionadas em casa de vegetação

\begin{tabular}{lccc}
\hline \multicolumn{1}{c}{ SUBSTRATO } & VOL.DERAIZ(mL) & COMP. DE RAIZ(cm) & CRESC.P/AÉREA(cm) \\
\hline LATOSSOLO+AREIA (S1) & $8,22 \mathrm{~b}^{*}$ & $15,46 \mathrm{~b}$ & $11,85 \mathrm{~b}$ \\
COMERCIAL (S2) & $3,21 \mathrm{c}$ & $7,58 \mathrm{c}$ & $6,61 \mathrm{c}$ \\
LATO+AREIA+CAMA AV. (S3) & $10,07 \mathrm{a}$ & $20,59 \mathrm{a}$ & $16,85 \mathrm{a}$ \\
\hline \multicolumn{1}{c}{ CV (\%) } & 10,4 & 24,91 & 19,91 \\
\hline
\end{tabular}

*Médias seguidas por letras minúsculas distintas na coluna, diferem significativamente entre si pelo teste de Duncan $(\alpha=0,05)$

O substrato S3 pela análise mostrou-se com características superiores tanto no caráter nutricional como nos aspectos químicos como $\mathrm{pH}, \mathrm{CTC}$ e ausência de alumínio trocável, o que pode ter sido favorável para o melhor desenvolvimento radicular.

Malavolta (1989) relatou que o fósforo possui papel fundamental no crescimento e desenvolvimento das plantas, por constituir compostos como o trifosfato de adenosina (ATP). Esse autor em outro estudo (MALAVOLTA, 1980) afirmou que a disponibilidade máxima de fósforo para a maioria das espécies, acontece quando o pH está em torno de 6,5, valor este apresentado pelo S3 e diferenciado pelos demais (S1 e S2).
Tal valor de $\mathrm{pH}$ está relacionado com a presença da cama de aviário como um dos constituintes da mistura do S3, uma vez que é comum o uso de cal para esterilização dos aviários e ao retirá-lo e utilizá-lo na mistura, faz com que ocorra elevação de seu $\mathrm{pH}$. Isso se torna benéfico quando se tem em outros ingredientes desta, a presença de material com $\mathrm{pH}$ mais ácido, como é o caso do latossolo vermelho.

O comprimento da parte aérea também foi significativo com o uso de $\mathrm{GA}_{3}$ (Figura 2), apresentando comportamento linear crescente com aumento da concentração de $\mathrm{GA}_{3}$. 
Figura 2. Comprimento parte aérea $(\mathrm{cm})$ de mudas de araçazeiros amarelos submetidos a quatro concentrações de $\mathrm{GA}_{3}\left(\mathrm{mg} \mathrm{L}^{-1}\right)$

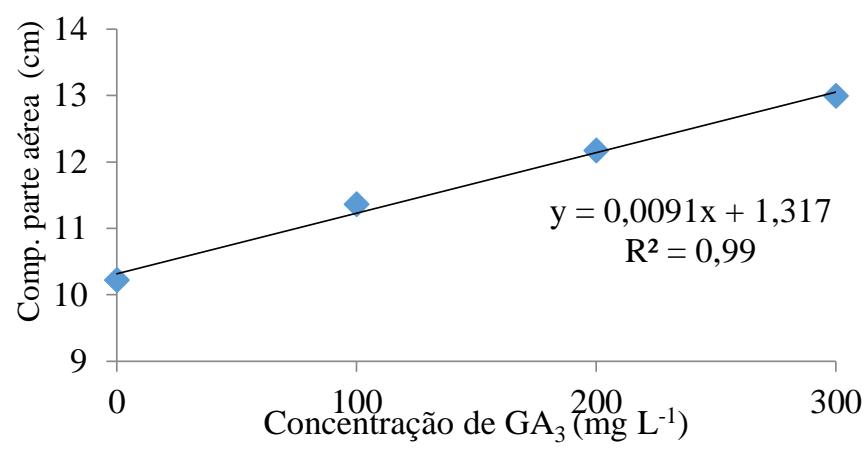

A área foliar e diâmetro do colo (Tabela 5) do araçazeiro amarelo mostraram interação significativa, sendo que em ambas as variáveis o substrato S3 foi superior em todas as concentrações de $\mathrm{GA}_{3}$ testadas. Por outro lado, ao analisar o efeito do $\mathrm{GA}_{3}$ em cada substrato visualizou-se para área foliar e diâmetro do colo diferenças entre as médias apenas com S3, tendo superioridade com as concentrações de 100 a $300 \mathrm{mg} \mathrm{L}^{-1}$ já que nos demais (S1 e S2) todas as concentrações foram estatisticamente semelhantes. Isso demonstra mais uma vez o efeito benéfico do $\mathrm{GA}_{3}$ quando se faz uso de substrato com características químicas adequadas para produção das mudas.

Tabela 5. Área foliar $\left(\mathrm{cm}^{2}\right)$ e diâmetro do colo $(\mathrm{mm})$ de mudas de araçazeiros amarelo submetidos a três tipos de substratos e quatro concentrações de $\mathrm{GA}_{3}\left(\mathrm{mg} \mathrm{L}^{-1}\right)$ no período de 180 dias acondicionadas em casa de vegetação

\begin{tabular}{|c|c|c|c|}
\hline \multicolumn{4}{|c|}{ ÁREA FOLIAR $(\mathrm{cm})$} \\
\hline & LATOSSOLO + & & \\
\hline \multirow[t]{2}{*}{$\mathrm{GA}_{3}\left(\mathrm{mg} \mathrm{L}^{-1}\right)$} & AREIA & COMERCIAL & LATO+AREIA+ CAMA AV. \\
\hline & S1 & S2 & S3 \\
\hline 0 & 1,41 a B * & 0,76 a $C$ & $1,88 \mathrm{~b} \mathrm{~A}$ \\
\hline 100 & 1,35 a B & 0,78 a $C$ & 2,33 a $A$ \\
\hline 200 & 1,49 a $B$ & 0,86 a $C$ & $2,10 a b A$ \\
\hline 300 & 1,56 a $B$ & 0,73 a $C$ & 2,27 a $A$ \\
\hline CV (\%) & & 24,7 & \\
\hline \multicolumn{4}{|c|}{ DIÂMETRO DO COLO (mm) } \\
\hline 0 & 1,42 a B* & 0,77 a $C$ & 1,88 b A \\
\hline 100 & 1,35 a $B$ & 0,78 a $C$ & 2,33 a $A$ \\
\hline 200 & 1,50 a $B$ & 0,86 a $C$ & $2,10 a b A$ \\
\hline 300 & 1,56 a $B$ & 0,73 a $\mathrm{C}$ & 2,27 a $A$ \\
\hline CV (\%) & & 3,96 & \\
\hline
\end{tabular}

*Médias seguidas por letras minúsculas distintas na coluna e maiúsculas na linha, diferem significativamente entre si pelo teste de Duncan $(\alpha=0,05)$.

As variáveis número, comprimento e largura de folhas e, teor de clorofila destas (Tabela 6) foram significativas quando se analisou isoladamente o fator substrato, com este apresentando superioridade com S3, seguido pelo substrato S1 e com menor com S2 para o araçazeiro amarelo. 
Tabela 6. Número de folhas, comprimento de folhas e largura de folhas $(\mathrm{cm})$ e teor de clorofila (índice de clorofila falker - ICF) de mudas de araçazeiros amarelo submetidos a três tipos de substratos no período de 180 dias, acondicionadas em casa de vegetação

\begin{tabular}{ccccc}
\hline SUBSTRATO & No FOLHAS & COMP. FOLHAS & LARG. FOLHAS & CLOROFILA \\
\hline LATOSSOLO+AREIA (S1) & $12,99 \mathrm{~b}^{*}$ & $2,44 \mathrm{~b}$ & $1,04 \mathrm{~b}$ & $33,79 \mathrm{~b}$ \\
COMERCIAL (S2) & $9,32 \mathrm{c}$ & $1,12 \mathrm{c}$ & $0,55 \mathrm{c}$ & $0,00 \mathrm{c}$ \\
LAT+AREIA+CAM AV. (S3) & $13,40 \mathrm{a}$ & $3,35 \mathrm{a}$ & $1,63 \mathrm{a}$ & $37,76 \mathrm{a}$ \\
\hline CV (\%) & 17,8 & 12,51 & 10,07 & 3,9 \\
\hline
\end{tabular}

*Médias seguidas por letras minúsculas distintas na coluna, diferem significativamente entre si pelo teste de Duncan $(\alpha=0,05)$.

Quando observado no araçazeiro vermelho, o volume de raízes, número de folhas, área foliar, largura de folhas, teor de clorofila e massa da matéria seca das folhas (Tabela 7) tiveram influência significativa também do fator substrato de maneira isolada, demonstrando-se novamente a superioridade das médias quando se fez uso do substrato S3.

Tabela 7. Crescimento em volume de raízes $(\mathrm{mL})$, número de folhas e área foliar $\left(\mathrm{cm}^{2}\right)$, largura de folhas $(\mathrm{cm})$, teor de clorofila (IFC), massa de matéria seca de folhas (M.S.F.) (g) e I.Q.D de mudas de araçazeiros vermelho submetidos a três tipos de substratos, no período de 180 dias, acondicionadas em casa de vegetação

\begin{tabular}{lcccc}
\hline \multirow{2}{*}{ VARIÁVEL } & LATOSSOLO+AREIA & COMERCIAL & AT+AREIA+CAMA AV. & CV \\
\cline { 2 - 5 } & $(\mathrm{S} 1)$ & $(\mathrm{S} 2)$ & $(\mathrm{S} 3)$ & $(\%)$ \\
\hline VOL. DE RAIZ $(\mathrm{mL})$ & $10,80 \mathrm{~b} *$ & $1,86 \mathrm{c}$ & $17,60 \mathrm{a}$ & 19,7 \\
No FOLHAS & $11,71 \mathrm{a}$ & $17,27 \mathrm{~b}$ & $10,23 \mathrm{a}$ & 26,3 \\
ÁREA FOLIAR $\left(\mathrm{cm}^{2}\right)$ & $12,47 \mathrm{~b}$ & $2,98 \mathrm{c}$ & $21,76 \mathrm{a}$ & 44,96 \\
LARG. FOLHAS $(\mathrm{cm})$ & $1,04 \mathrm{~b}$ & $0,54 \mathrm{c}$ & $1,44 \mathrm{a}$ & 3,5 \\
CLOROFILA (IFC) & $28,61 \mathrm{~b}$ & $1,57 \mathrm{c}$ & $32,98 \mathrm{a}$ & 22,83 \\
M.S.F. (g) & $0,84 \mathrm{~b}$ & $0,20 \mathrm{c}$ & $1,42 \mathrm{a}$ & 12 \\
I.Q.D & $1,32 \mathrm{~b}$ & $1,55 \mathrm{ab}$ & $1,72 \mathrm{a}$ & 21,85 \\
\hline
\end{tabular}

*Médias seguidas por letras minúsculas distintas na coluna, diferem significativamente entre si pelo teste de Duncan $(\alpha=0,05)$.

Tal comportamento reforça os benefícios que este substrato possui para produção de mudas por apresentar características químicas favoráveis para o crescimento das mudas dos araçazeiros amarelo e vermelho.

Por outro lado, nas variáveis largura e massa da matéria seca das folhas houve significância estatística no fator concentração de $\mathrm{GA}_{3}$ de maneira isolada (Figuras $3 \mathrm{~A}$ e 3B, respectivamente). $\mathrm{Na}$ largura de folhas, $\mathrm{O}$ comportamento obtido com as médias teve efeito linear decrescente, demonstrando-se que com o incremento na concentração de $\mathrm{GA}_{3}$ aplicada reduziu o alongamento das mesmas.

Isso pode estar relacionado ao fato de que com aumento na concentração de $\mathrm{GA}_{3}$, este estimula o alongamento em altura da planta, fazendo com que as reservas sejam destinadas a esse crescimento vertical, o que reduz o crescimento em largura das folhas. 
Figura 3. Largura de folhas ( $\mathrm{cm}$ ) (Figura 3A), massa de matéria seca de folhas (g) (Figura 3B) de mudas de araçazeiros vermelhos submetidos a quatro concentrações de $\mathrm{GA}_{3}\left(\mathrm{mg} \mathrm{L}^{-1}\right)$
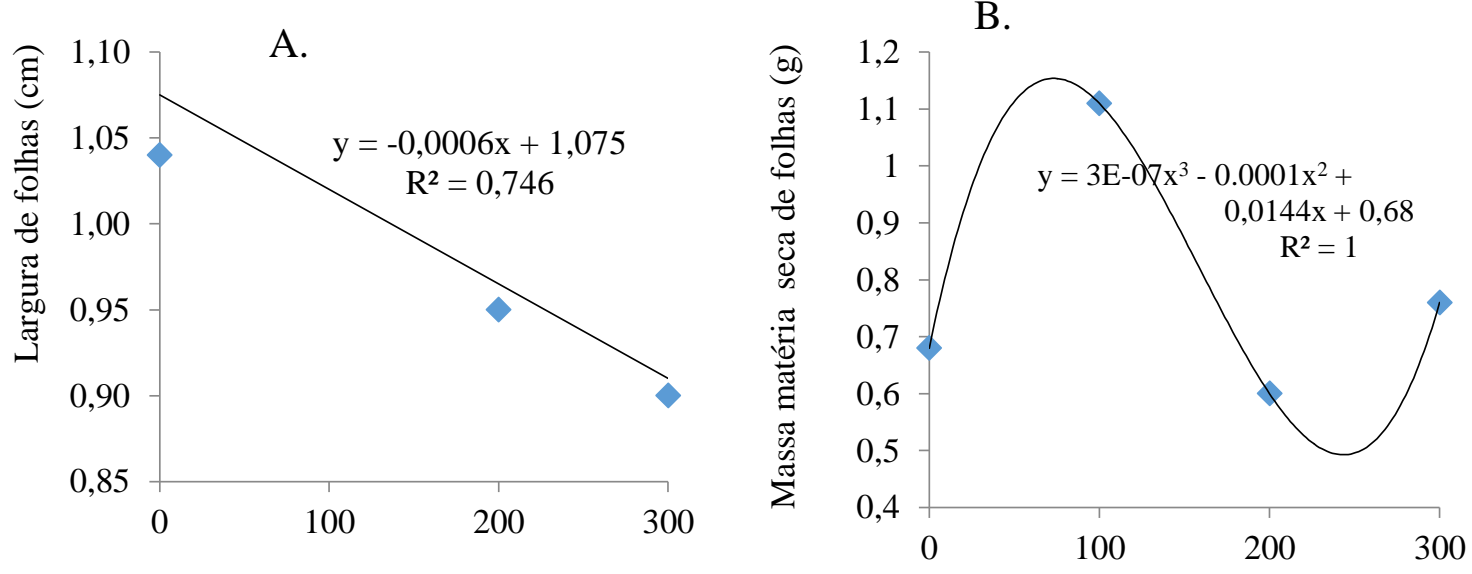

Concentração de $\left.\mathrm{GA}_{3}(\mathrm{mg}) \mathrm{L}^{-1}\right)$

A massa da matéria seca de folhas apresentou-se comportamento cúbico, havendo máxima resposta em torno de $90 \mathrm{mg} \mathrm{L}^{-1}$ e mínima em $230 \mathrm{mg} \mathrm{L}^{-1}$, o que novamente reforça a hipótese da planta em direcionar fotoassimilados para outra região, resultando no menor crescimento foliar em decorrência de seu aumento em altura, nas menores concentrações.

Para as variáveis comprimento de raízes e comprimento da parte aérea (Tabela 8), diâmetro do colo e comprimento das folhas (Tabela 9) houve interação significativa entre os fatores testados para o araçazeiro vermelho.

Este comprimento das raízes mostrou superioridade com o substrato S1 e S3 nas concentrações de 200 e $300 \mathrm{mg} \mathrm{L}^{-1}$ e, a mesma resposta para concentração de $100 \mathrm{mg} \mathrm{L}^{-1}$ com S3. Para concentração $0 \mathrm{mg} \mathrm{L}^{-1}$, os substratos assemelharam-se estatisticamente entre si, reforçando aqui a importância de utilizar a interação substrato $X \mathrm{KA}_{3}$ visando proporcionar maior desenvolvimento para muda. Fato este observado com S3 que teve as maiores médias desta variável na concentração de $100 \mathrm{mg} \mathrm{L}^{-1} \mathrm{e}$, em S2 com 0 e $300 \mathrm{mg} \mathrm{L}^{-1}$. Para S1, todas as concentrações apresentaram médias em comprimento de raízes estatisticamente semelhantes (Tabela 8).

Tabela 8. Comprimento de raízes $(\mathrm{cm})$, comprimento da parte aérea $(\mathrm{cm})$ de mudas de araçazeiros vermelho submetidos a três tipos de substratos e quatro concentrações de $\mathrm{GA}_{3}\left(\mathrm{mg} \mathrm{L}^{-1}\right)$ no período de 180 dias acondicionadas em casa de vegetação

\begin{tabular}{|c|c|c|c|}
\hline \multicolumn{4}{|c|}{ COMPRIMENTO DE RAÍZES (cm) } \\
\hline \multirow{2}{*}{$\mathrm{GA}_{3}\left(\mathrm{mgL}^{-1}\right)$} & LATOSSOLO + AREIA & COMERCIAL & LATO+AREIA+ CAMA AV. \\
\hline & S1 & S2 & S3 \\
\hline 0 & 15,93 а $A^{*}$ & 13,60 a $A$ & 16,82 b A \\
\hline 100 & 17,65 a $B$ & 7,55 b C & 22,90 a $A$ \\
\hline 200 & 14,50 a $A$ & 8,04 b B & 17,86 b A \\
\hline 300 & 13,73 a $A B$ & $10,54 a b B$ & 15,81 b A \\
\hline CV (\%) & & 23,3 & \\
\hline \multicolumn{4}{|c|}{ COMPRIMENTO DA PARTE AÉREA $(\mathrm{cm})$} \\
\hline 0 & 9,68 a $A^{*}$ & 7,21 a $B$ & 10,37 c A \\
\hline 100 & 11,28 a $B$ & 6,43 a $C$ & $14,63 \mathrm{~b} \mathrm{~A}$ \\
\hline 200 & 12,18 a $A$ & 6,68 a $B$ & 14,31 b A \\
\hline 300 & 12,96 a $\mathrm{B}$ & 8,1 a C & 18,21 a $A$ \\
\hline
\end{tabular}

*Médias seguidas por letras minúsculas distintas na coluna e maiúsculas na linha, diferem significativamente entre si pelo teste de Duncan $(\alpha=0,05)$. 
Ainda observando a Tabela 8, o comprimento da parte aérea, com o substrato S3 teve superioridade com araçazeiro vermelho na concentração $300 \mathrm{mg} \mathrm{L}^{-1}$, sendo que para os demais substratos as médias não diferiram estatisticamente entre si. Dentro de cada substrato, obteve-se médias com diferenças estatísticas para esta variável somente com S3, cuja superioridade foi com $300 \mathrm{mg} \mathrm{L}^{-1}$. Dessa forma, visualiza-se que o efeito esperado do $\mathrm{GA}_{3}$ só ocorre se no meio em que a muda foi inserida houver condições propícias para que a mesma expresse os fatores genéticos para maior crescimento, sendo estas ligadas principalmente as características químicas do substrato.

No diâmetro do colo do araçazeiro vermelho, o substrato S3 foi superior aos demais quando se aplicaram as concentrações de 100, 200 e $300 \mathrm{mg} \mathrm{L}^{-1}$. Com $0 \mathrm{mg} \mathrm{L}^{-1}$ os substratos não diferiram estatisticamente entre $\mathrm{si}$, sendo $\mathrm{o}$ mesmo ocorrido com S1 analisando as concentrações de $\mathrm{GA}_{3}$. Por outro lado, avaliandose dentro de cada substrato, no S2 as maiores médias foram com 0,200 e $300 \mathrm{mg} \mathrm{L}^{-1}$ e no S3 com aplicação do produto $\mathrm{GA}_{3}$ em qualquer das concentrações (Tabela 9). Este diâmetro do colo, faz-se importante quando se pensa em utilizar tais mudas como porta-enxerto, já que vem sendo testado o araçazeiro com a goiabeira, pois alguns genótipos apresentam maior tolerância a nematoides (CARNEIRO et al., 2007).

Com o comprimento das folhas, a superioridade do $\mathrm{GA}_{3}$ foi repetida em relação aos demais substratos, sendo esta em todas as concentrações de $\mathrm{GA}_{3}$. Todavia, com S1 e S2 as concentrações não diferiram estatisticamente entre si, mas para S3 as maiores médias foram com 100 e $300 \mathrm{mg} \mathrm{L}^{-1}$ com o araçazeiro vermelho (Tabela 9).

Tabela 9. Diâmetro do colo $(\mathrm{mm})$ e comprimento de folhas $(\mathrm{cm})$ de mudas de araçazeiros vermelho submetidos a três tipos de substratos e quatro concentrações de $\mathrm{GA}_{3}\left(\mathrm{mg} \mathrm{L}^{-1}\right)$ no período de 180 dias acondicionadas em casa de vegetação

\begin{tabular}{|c|c|c|c|}
\hline \multicolumn{4}{|c|}{ DIÂMETRO DO COLO (mm) } \\
\hline \multirow{2}{*}{$\mathrm{GA}_{3}\left(\mathrm{mgL}^{1}\right)$} & LATOSSOLO + AREIA & COMERCIAL & LATO+AREIA+ CAMA AV. \\
\hline & S1 & S2 & S3 \\
\hline 0 & 1,56 a $A^{*}$ & 1,07 a $A$ & 1,79 b A \\
\hline 100 & 1,68 a $B$ & $0,62 \mathrm{~b} \mathrm{C}$ & $2,14 a b A$ \\
\hline 200 & 1,54 a B & $0,77 \mathrm{ab} C$ & $1,98 a b A$ \\
\hline 300 & 1,51 a $B$ & $0,89 \mathrm{ab} \mathrm{C}$ & 2,23 a $A$ \\
\hline CV (\%) & & 5,03 & \\
\hline \multicolumn{4}{|c|}{ COMPRIMENTO DE FOLHAS (cm) } \\
\hline 0 & 1,88 a $A^{*}$ & 1,04 a B & $2,13 \subset A$ \\
\hline 100 & 2,12 a $B$ & 0,86 a C & 3,08 a $A$ \\
\hline 200 & 1,94 a B & 0,88 a $B$ & 2,42 bc $A$ \\
\hline 300 & 1,90 a $B$ & 1,10 a $C$ & $2,73 a b \mathrm{~A}$ \\
\hline CV (\%) & & 17,22 & \\
\hline
\end{tabular}

*Médias seguidas por letras minúsculas distintas na coluna e maiúsculas na linha, diferem significativamente entre si pelo teste de Duncan $(\alpha=0,05)$.

Avaliando-se as massas da matéria seca de folhas, caule e raízes do araçazeiro amarelo obteve-se diferenças estatísticas quando analisado $\mathrm{o}$ substrato isoladamente. $\mathrm{O}$ incremento ocorrido com estas três variáveis teve efeito com superioridade estatística para o substrato S3, seguido pelo S1 e por último com S2 (Tabela 10). 
Tabela 10. Massa de matéria seca de folhas (M.S.F.), massa de matéria seca de caule (M.S.C.), massa de matéria seca de raízes (M.S.R.) (g) de mudas de araçazeiros amarelo submetidos a três tipos de substratos no período de 180 dias, acondicionadas em casa de vegetação

\begin{tabular}{cccc}
\hline SUBSTRATO & M.S.F. (g) & M.S.C. (g) & M.S.R. (g) \\
\hline LATOSSOLO+AREIA (S1) & $1,03 \mathrm{~b}^{*}$ & $0,64 \mathrm{~b}$ & $1,63 \mathrm{~b}$ \\
COMERCIAL (S2) & $0,16 \mathrm{c}$ & $0,14 \mathrm{c}$ & $0,18 \mathrm{c}$ \\
LATO+AREIA+CAMA AV. (S3) & $2,16 \mathrm{a}$ & $1,50 \mathrm{a}$ & $3,61 \mathrm{a}$ \\
\hline CV (\%) & 19,52 & 14,02 & 16,29 \\
\hline
\end{tabular}

*Médias seguidas por letras minúsculas distintas na coluna, diferem significativamente entre si pelo teste de Duncan $(\alpha=0,05)$.

Para o índice de qualidade de Dickson houve interação significativa entre os fatores, com as concentrações de $\mathrm{GA}_{3}$ não diferindo suas médias obtidas entre as concentrações de $\mathrm{GA}_{3}$ para S1 e S3 e, com maior valor para S2 com 300 $\mathrm{mg} \mathrm{L}^{-1}$ (Tabela 11). Já ao analisar as concentrações de $\mathrm{GA}_{3}$ em cada substrato estes só diferiram estatisticamente entre si com $300 \mathrm{mg} \mathrm{L}^{-1}$, cujas maiores médias foram obtidas com S2 e S3.

Entretanto, quando analisados O I.Q.D de mudas de araçazeiros vermelhos, este apresentou-se significativo para os dois fatores de maneira isolada, cujas médias foram superiores quando utilizados o substrato S2 e S3 (Tabela 7). Quando testado as concentrações de $\mathrm{GA}_{3}$ (Figura 8), essa apresentou-se comportamento cúbico, também havendo máxima resposta em torno de $90 \mathrm{mg} \mathrm{L}^{-1}$ e mínima em $230 \mathrm{mg} \mathrm{L}^{-1}$.

Tabela 11. Índice de qualidade de mudas de araçazeiros amarelo submetidos a três tipos de substratos e quatro concentrações de $\mathrm{GA}_{3}\left(\mathrm{mg} \mathrm{L}^{-1}\right)$ no período de 180 dias acondicionadas em casa de vegetação

\begin{tabular}{|c|c|c|c|}
\hline \multirow{3}{*}{$\mathrm{GA}_{3}\left(\mathrm{mgL}^{-1}\right)$} & \multicolumn{3}{|c|}{ COMERCI } \\
\hline & LATOSSOLO + AREIA & $\mathrm{AL}$ & LATO+AREIA+ CAMA AV \\
\hline & S1 & S2 & S3 \\
\hline \multirow{3}{*}{0} & & $1,17 b$ & \\
\hline & 2,06 a $A^{*}$ & $A$ & 1,82 a $A$ \\
\hline & & $1,66 \mathrm{~b}$ & \\
\hline \multirow[t]{2}{*}{100} & 1,48 a $A$ & $A$ & 2,24 a $A$ \\
\hline & & $2,00 \quad b$ & \\
\hline \multirow[t]{2}{*}{200} & 1,30 a $A$ & A & 1,70 a $A$ \\
\hline & & $3,44 \quad a$ & \\
\hline 300 & 1,50 a $B$ & $A$ & 2,30 a $A B$ \\
\hline
\end{tabular}

* Médias seguidas por letras minúsculas distintas na coluna e maiúsculas na linha, diferem significativamente entre si pelo teste de Duncan $(\alpha=0,05)$. 
Figura 4. Índice de qualidade de Dickson de mudas de araçazeiros vermelhos submetidos a quatro concentrações de GA3 (mg t$\left.{ }^{-1}\right)$

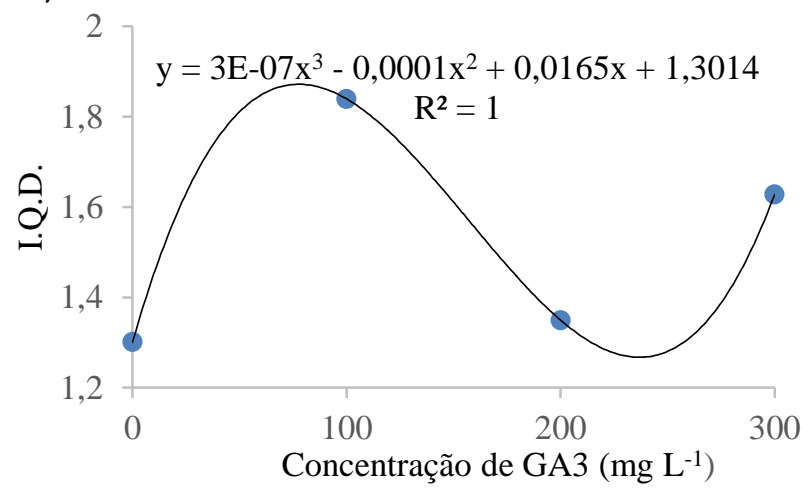

O índice de qualidade de Dickson é mencionado na literatura como promissora medida morfológica integrada (JOHNSON; CLINE, 1991) e apontado como bom indicador da qualidade de mudas, pois inclui parâmetros morfológicos de altura, diâmetro e biomassa que são parâmetros importantes, considerando-se quanto maior o valor do índice melhor é o padrão de qualidade de mudas (COSTA et al., 2011).

Quando observado a massa da matéria seca de caule e das raízes (Tabela 12) do araçazeiro vermelho, verificou-se presença de interação significativa quanto ao substrato $X$ $\mathrm{GA}_{3}$.

Tabela 12. Massa seca de caules e massa seca de raízes ( $\mathrm{g}$ ) de mudas de araçazeiros vermelho submetidos a três tipos de substratos e quatro concentrações de $\mathrm{GA}_{3}\left(\mathrm{mg} \mathrm{L}^{-1}\right)$ no período de 180 dias acondicionadas em casa de vegetação

\begin{tabular}{cccc}
\hline \multicolumn{4}{c}{ Massa seca de caules $(\mathrm{g})$} \\
\hline \multirow{2}{*}{$\mathrm{GA3}\left(\mathrm{mgL}^{-1}\right)$} & LATOSSOLO + AREIA & COMERCIAL & LATO+AREIA+ CAMA AV. \\
\cline { 2 - 4 } & S1 & S2 & S3 \\
\hline 0 & 0,59 a A* & 0,16 a B & $0,80 \mathrm{c} \mathrm{A}$ \\
100 & 0,91 a B & 0,13 a C & $1,57 \mathrm{~b} \mathrm{~A}$ \\
200 & 0,63 a B & 0,17 a C & $1,32 \mathrm{~b} \mathrm{~A}$ \\
300 & 0,69 a B & 0,23 a C & 2,23 a A \\
\hline CV (\%) & 8.91 \\
\hline \multicolumn{4}{c}{ Massa seca de raízes (g) } \\
\hline 0 & 0,43 a B & $2,72 \mathrm{~b} \mathrm{~A}$ \\
100 & 2,25 a A* & 0,15 a C & 4,52 a A \\
200 & 2,58 a B & 0,24 a C & 4,18 ab A \\
300 & 1,64 a B & 0,29 a C & 5,27 a A \\
\hline CV (\%) & 1,39 a B & 10,87 \\
\hline
\end{tabular}

*Médias seguidas por letras minúsculas distintas na coluna e maiúsculas na linha, diferem significativamente entre si pelo teste de Duncan $(\alpha=0,05)$.

No caso das respostas obtidas com a massa da matéria seca das raízes e do caule é possível observar a mesma superioridade do $\mathrm{S} 3 \mathrm{em}$ quase todas as concentrações de $\mathrm{GA}_{3}$ testadas, exceção apenas para $0 \mathrm{mg} \mathrm{L}^{-1}$, que teve o mesmo efeito de maior média, também com S1.

No caso de cada substrato, as médias para massa de matéria seca dos caules e raízes igualaram-se estatisticamente com S1 e S2 nas concentrações testadas, sendo para S3 com superioridade na concentração 0 e, de 100 a 300 $\mathrm{mg} \mathrm{L}^{-1}$, respectivamente (Tabela 12 ).

Casagrande Jr. et al. (1996) produzindo mudas de araçazeiro afirmaram que, com a adição de materiais orgânicos ocorre favorecimento do crescimento destas, com os melhores resultados obtidos pelo uso do vermicomposto (adubo de minhocultura) nas proporções de 1:1 e 3:1 v/v.

$\mathrm{Na}$ produção de mudas de maracujazeiro amarelo, a mistura de materiais orgânicos como parte constituinte do substrato, proporcionaram 
maior crescimentos das mesmas (NEGREIROS et al., 2004).

Zietemann e Roberto (2007), afirmaram que a presença de areia e matéria orgânica no substrato para produção de mudas equilibra as propriedades físicas necessárias para o desenvolvimento das plantas como a porosidade e drenagem e, também nas propriedades químicas e biológicas. Isso foi demonstrado com o S3, talvez em virtude de a mistura envolver tanto areia quanto material com matéria orgânica.

Dessa forma, o substrato S3 que é composto da mistura de latossolo, areia e cama de aviário influenciou na disponibilidade de nutrientes, capacidade de retenção de água e porosidade, permitindo o crescimento radicular da muda e consequentemente $\mathrm{o}$ desenvolvimento da mesma que associado ao uso da giberelina possibilitou resultados satisfatórios para a maioria das variáveis do araçazeiro amarelo e vermelho.

\section{CONCLUSÃO}

$\mathrm{O}$ uso da concentração de $300 \mathrm{mg} \mathrm{L}^{-1}$ de $\mathrm{GA}_{3}$ com substrato S3 pode ser recomendado para produção de mudas de araçazeiro amarelo e vermelho.

\section{AGRADECIMENTOS}

À Coordenação de Aperfeiçoamento de Pessoal de Nível Superior (Capes) e Universidade Tecnológica Federal do Paraná (UTFPR), pela concessão de bolsas, estrutura e materiais necessários à realização do experimento.

\section{REFERÊNCIAS}

BIASI, L. A.; COSTA, G. Propagação vegetativa de Lippia alba. Ciência Rural, v. 33, n. 3, p. 455-459, $2003 . \quad \quad$ http://dx.doi.org/10.1590/S0103$\underline{84782003000300010}$

CASAGRANDE JR., J. G.; VOLTOLINI, J. A., HOFFMANN, A; FACHINELLO, J. C. Efeito de materiais orgânicos no crescimento de mudas de araçazeiro (psidium cattleyanum sabine). Revista Brasileira de Agrociência, v.2, n. 3, pag.187-191, 1996

\section{HTTP://DX.DOI.ORG/10.18539/CAST.V2I3.177}

CARNEIRO, R. M.D.G.; CIROTTO, P. A.; QUINTANILHA, A. P.; SILVA, D. B.; CARNEIRO, R. G. Resistance to Meloidogyne mayaguensis in Psidium spp. Accessions and their Grafting Compatibility with P. guajava cv. Paluma.
Fitopatologia Brasileira, v. 32, n.4, 2007. http://dx.doi.org/10.1590/S0100$\underline{41582007000400001}$

COSTA, E.; GUSTAVO, L.; DURANTE, Y.; NAGEL, P. L.; REZENDE, C. Qualidade de mudas de berinjela submetida a diferentes métodos de produção. Revista Ciência Agronômica, v.42, n.4, p. 10171025, 2011. Disponível em: $<$ http://www.ccarevista.ufc.br/seer/index.php/cc arevista/article/view/1331/637>. Acesso em: 03 out. 2016.

CRUZ, C.D. Programa Genes: biometria. Editora UFV, 2006. 382p.

DANNER, M. A.; CITADIN, I.; SASSO, S. A. Z.; SACHET, M. R.; AMBRÓSIO, R. Fenologia da floração e frutificação de mirtáceas nativas da floresta com araucária. Revista Brasileira de Fruticultura, v. 32, n. 1, p. 291-295, 2010. Disponível em: $<$ http://www.scielo.br/pdf/rbf/2010nahead/aop0 0810.pdf>. Acesso em: 03 out. 2016.

DICKSON, A.; LEAF, A. L.; HOSNER, J. F. Quality appraisal of white spruce and white pine seedling stock in nurseries. Forestry Chronicle, v. 36, p. 1013, 1960. doi: 10.5558/tfc36010-1.

FRANZON, R. C.; CAMPOS, L. Z. O.; PROENÇA, C. E. B.; SOUSA-SILVA, J. C. Araçás do Gênero Psidium: principais espécies, ocorrência, descrição e usos. EMBRAPA, 2009. 47p. (Documentos, 266).

FONTES, P. C. R.; LOURES, J. L.; GALVÃO, J. C. C.; CARDOSO, A. A.; MANTOVANI, E. C. Produção e qualidade do tomate produzido em substrato, no campo e em ambiente protegido. Horticultura Brasileira, v. 22, n. 3, p. 614-619, 2004. Disponível em: $<$ http://www.scielo.br/pdf/\%0D/hb/v22n3/a23v2 2n3.pdf>. Acesso em: 03 out. 2016.

HEINZMANN, B. M.; BARROS, F. M. C. Potencial Das Plantas Nativas Brasileiras Para $O$ Desenvolvimento De Fitomedicamentos Tendo Como Exemplo Lippia Alba (Mill.) N. E. Brown (Verbenaceae). Revista Saúde, v. 33, n. 1, p. 4348 , 2007.

\section{http://dx.doi.org/10.5902/223658346463}

HISTER, C.; TEDESCO, S. Estimativa da viabilidade polínica de araçazeiro (Psidium cattleianum 
Sabine) através de distintos métodos de coloração. Revista Brasileira de Plantas Medicinais, v. 18, n. 1, p. 135-141, 2016. http://dx.doi.org/10.1590/1983-084X/15 081

JOHNSON, J.D.; CLINE, M.L. Seedling quality of southern pines. In: DURYEA, M.L.; DOUGHERTY, P.M. (eds.). Forest regeneration manual. Netherlands: Klumer Academic, 1991. p. 143162.

KINUPP, V. F.; BARROS, I. B. I. Teores de proteína e minerais de espécies nativas, potenciais hortaliças e frutas. Ciencia e Tecnologia de Alimentos. Campinas, v. 28, n. 4, p. 846-857, 2008. http://hdl.handle.net/10183/20761

LORENZI, H. Árvores brasileiras: manual de identificação e cultivo de plantas arbóreas nativas do Brasil. Nova Odessa: Plantarum de Estudos da Flora, 1992. v.1.

MALAVOLTA, E. ABC da adubação. São Paulo: Agronômica Ceres, 1989. 292p.

MALAVOLTA, E. Elementos de nutrição mineral de plantas. São Paulo: Agronômica Ceres, 1980. $251 \mathrm{p}$.

NEGREIROS, J. R. S.; ÁLVARES, V. S.; BRAGA, L. R.; BRUCKNER, C. $H$. Diferentes substratos na formação de mudas de maracujazeiro-amarelo. Revista Ceres, v. 51, n. 294, p. 243-249, 2004. Disponível em: $<$ http://www.ceres.ufv.br/ojs/index.php/ceres/ar ticle/view/2956>. Acesso em: 03 out. 2016.

OLIVEIRA, J.R.; SOUZA, F.V.P.; SILVA, U.T.G.; DUARTE, N.F.; PINTO, S.I.C. Saturação por bases para o Cultivo do Cedro Australiano. Global Science Technology, v.08, n.02, p.96-102, 2015. Disponível

em: $<$ http://rv.ifgoiano.edu.br/periodicos/index.php/ gst/article/view/737/467>. Acesso em: 03 out. 2016.

PAIVA SOBRINHO, S.; LUZ, P. B.; SILVEIRA, T. L. S.; RAMOS, D.T.; NEVES, L.G.; BARELLI, M. A. A. Substratos na produção de mudas de três espécies arbóreas do cerrado. Revista Brasileira de Ciências Agrárias, v. 5, n. 2, p. 238-243, 2010. DOI 10.5039/agraria.v5i2a741

RASEIRA, M. C. B.; RASEIRA, A. Contribuição ao estudo do araçazeiro, Psidium cattleyanum. Pelotas: EMBRAPA-CPACT, 1996. 95 p.
SCALON, S. P. Q.; LIMA, A. A.; SCALON FILHO, H.; VIEIRA, M. C. Germinação de sementes e crescimento inicial de mudas de Campomanesia adamantium camb.: Efeito da lavagem, temperatura e de bioestimulantes. Revista Brasileira de Sementes, v. 31, n. 2, p. 96-103, 2009. http://dx.doi.org/10.1590/s0101$\underline{31222009000200011}$

TAIZ, L.; ZEIGER, E. Fisiologia vegetal. Porto Alegre: Artmed, 2013. 135 p.

TOMAZ, Z. F. P.; GALARÇA, S. P.; LIMA, C. S. M.; BETEMPS, D.L.; MICHEL ALDRIGHI GONÇALVES, M.A.; RUFATO, A.R. Tratamentos PréGerminativos em Sementes De Araçazeiro (Psidium cattleyanum Sabine L.). Revista Brasileira de Agrociência, v. 17, n. 1-4, p. 60-65, 2011.

HTTP://DX.DOI.ORG/10.18539/CAST.V17I1.2032

TORRES, R. C.; BORGES, K. C. A. S. Ação da giberelina no crescimento de pimenta (Capsicum frutescens). Cadernos UniFOA, v. 17, p. 89-94, $2013 . \quad$ Disponível em: $<$ http://web.unifoa.edu.br/cadernos/ojs/index.p hp/cadernos/article/view/28/11>. Acesso em: 03 out. 2016.

WAGNER JÚNIOR, A; SANTOS, C. E. M.; SILVA, J. O. C.; PIMENTEL, L. D.; BRUCKNER, C. H. Influência do substrato e do ácido giberélico no desenvolvimento inicial do pessegueiro progênie 290. Revista Brasileira de Agrociência (UFPEL), v. 18, p. 11-20, 2012. HTTP://DX.DOI.ORG/10.18539/CAST.V18I1.2483

ZIETEMANN, C.; ROBERTO, S. R. Produção de mudas de goiabeira psidium guajava em Diferentes substratos. Revista Brasileira De Fruticultura, v. 29, n. 1, p. 137-142, 2007. Disponivel em: $<$ http://www.scielo.br/pdf/\%0D/rbf/v29n1/a30v 29n1.pdf>. Acesso em: 03 out. 2016.

ZONTA, E. P.; MACHADO, A. A. Sanest - Sistema de análise Estatística para Microcomputadores. UFPel, 1984.

Recebido para publicação em 26/09/2017

Revisado em 28/03/2018

Aceito em 02/04/2018 